Historic, archived document

Do not assume content reflects current scientific knowledge, policies, or practices. 


AND VEGETABLES

MARKETING BULLETIN NO. 56 AGRICULTURAL MARKETING SERVICE U:S. DEPARTMENT OF AGRICULTURE

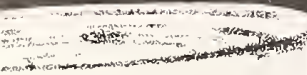
BUIT SECTOS
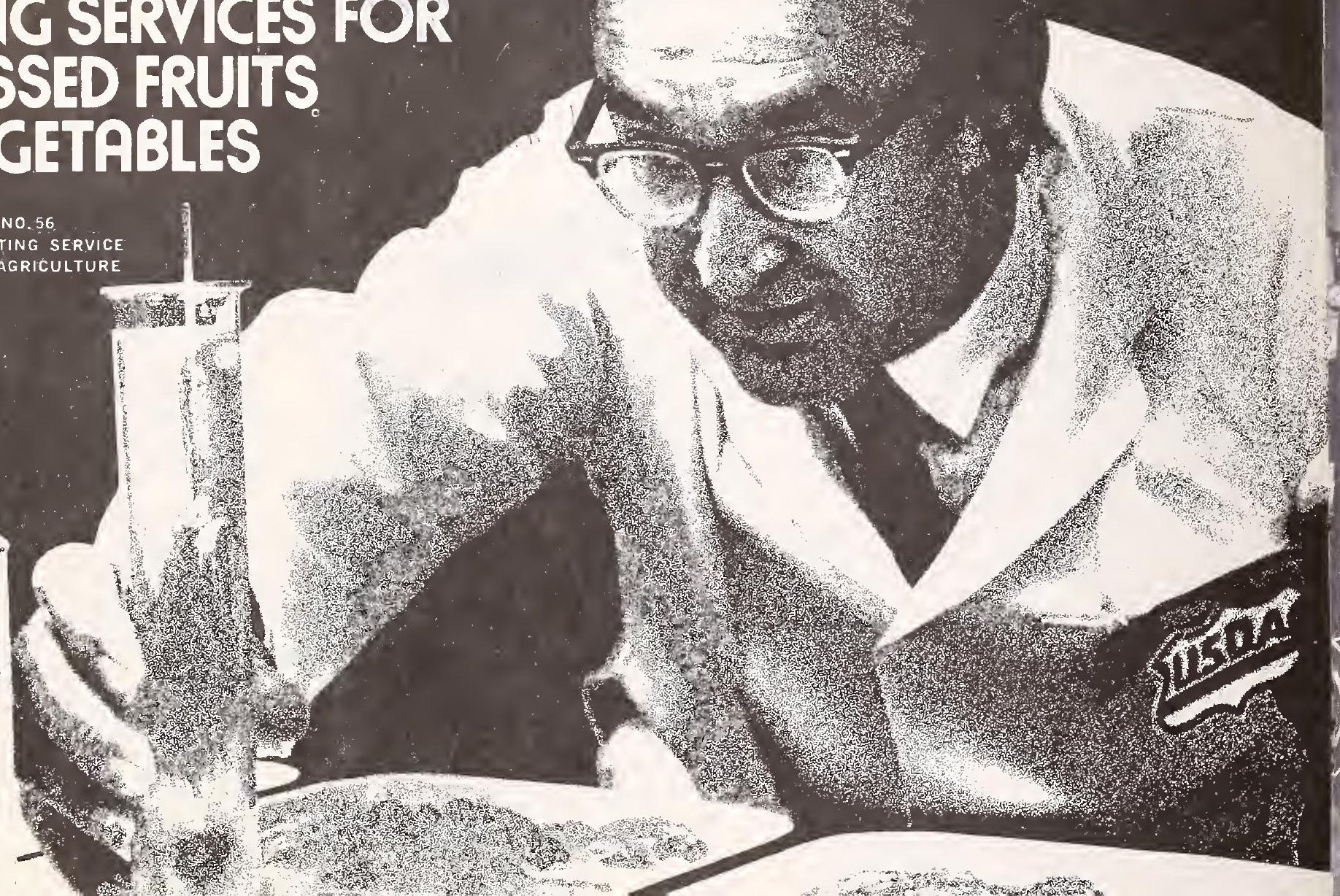


\section{INSPECTION AND GRADING SERVICES FOR PROCESSED FRUITS AND VEGETABLES}

Whether you are a processor, a buyer, or a seller of canned, frozen, dried, or dehydrated fruits and vegetables, there is an inspection service to meet your needs. The U.S. Department of Agriculture provides official inspection and grading of these and related products like jams, jellies, peanut butter, tea, and coffee for anyone who has a financial interest in any of these products. Administered by the Fruit and Vegetable Division of USDA's Agricultural Marketing Service, the services are available on request and for a fee to cover the cost of the service.

USDA's inspection services can be based on official U.S. standards or on your own quality or condition specifications.

If inspection is based on U.S. grade standards, each of your shipments can be covered by an official certificate showing that the product meets a USDA grade.

If there are no U.S. standards for your product or if you request a quality or condition inspection based on your own specifications, the certificate will state the product's quality or condition on that basis.

By the same token, buyers can use USDA inspection to determine whether the terms of their contracts or purchase orders have been met. Volume food buyers can order food by U.S. grade and require USDA inspection before accepting delivery. USDA inspectors will certify that the product meets the order specifications and is in good condition. USDA will also check the condition of the food containers.

USDA inspection can provide official quality and condition certification to help settle claims for damage incurred in transit or storage. It can complement a processor's quality control program from the preparation of the raw material to the warehousing of the finished product. And bankers can ask USDA to certify the quality, quantity, and condition of products posted as collateral in support of loans.

There are four basic inspection services available. Users can choose the type of service that is tailored to their needs.

Continuous Inspection-One or more inspectors can be assigned to a plant at all times it is operating. The inspector makes continuous in-process checks of preparation, processing, and packing operations and certifies the grade (or quality) and condition of the finished product. 
Pack Certification-Under this program, the inspector is not necessarily present during all operating shifts. He may inspect and certify the entire pack under a cooperative Quality Assurance Program in plants which qualify or he may inspect and certify only designated portions of production.

Lot Inspection-The inspector will check specific lots for quality and condition of the food product and container. The lot can be any size and located in places other than a processing plant.

Unofficial Sample Inspection-Inspection will be made of samples which you select and submit to the nearest USDA inspection office.

In addition, USDA offers volume buyers a service under which USDA representatives will help them write their purchase specifications and will certify the quality and condition of their orders either prior to shipment or when they arrive.

These inspection and grading services play an important role in the orderly marketing of canned, frozen, and dried fruits and vegetables. And the application of the U.S. standards and other specifications by highly trained USDA inspectors assures processors, buyers, and sellers of an impartial, third-party certification of quality.

\section{U.S. Grade Standards- Yardsticks of Quality}

Specialists in USDA have developed U.S. grade standards for some 150 processed fruit and vegetable products.

These U.S. standards are the yardsticks used by USDA's inspectors when you request official inspection based on the U.S. grades. The standards also provide the industry with a common trading language, a guide for in-plant quality control, and a convenient basis for sales.

In addition to certifying the quality, quantity, and condition of fruit and vegetable products, USDA inspectors will also check the condition of the food containers.

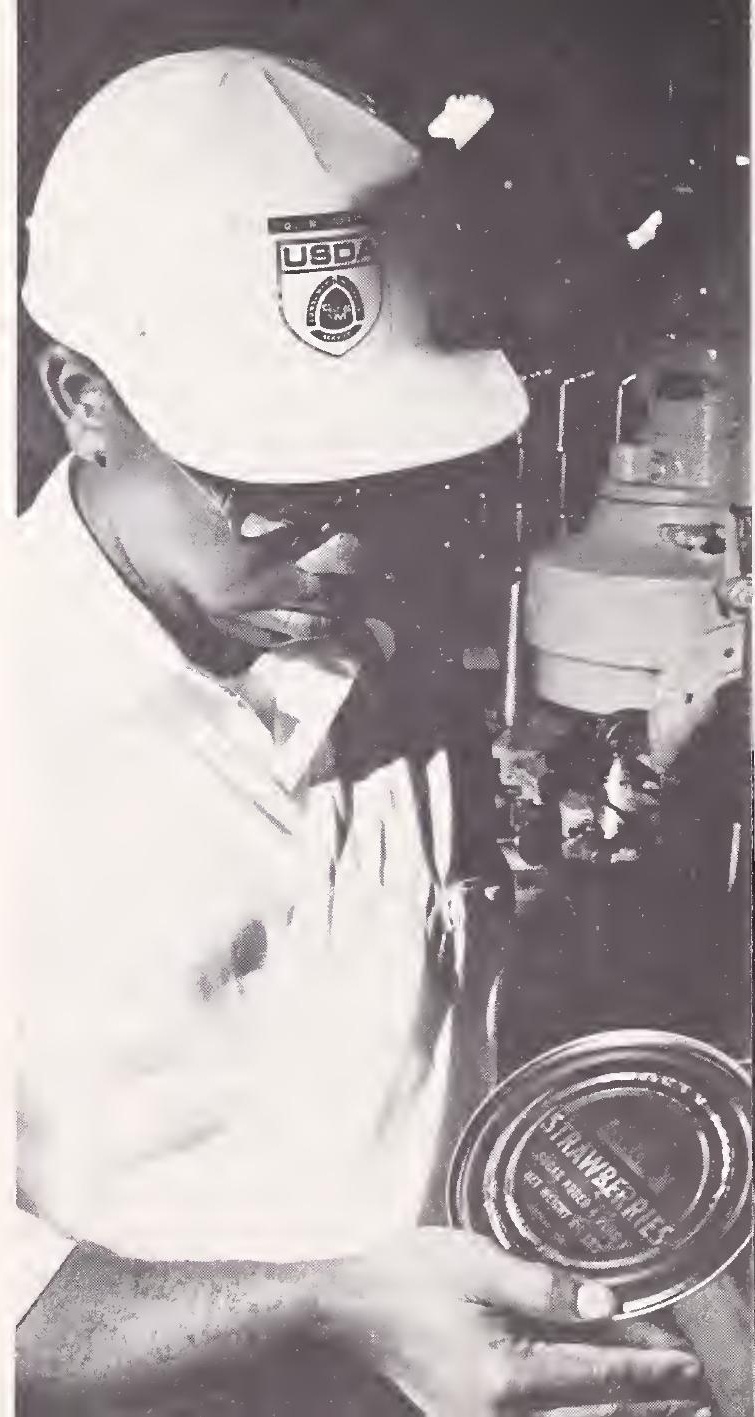


USDA grade standards for most processed fruits and vegetables describe three quality levels:

- U.S. Grade A or U.S. Fancy means top or best quality in color, flavor, uniformity of size and shape, tenderness, and lack of defects-for use when appearance is most important.

- U.S. Grade B or U.S. Choice (for fruits) or U.S. Extra Standard (for vegetables) means good qualitysuitable for most purposes.

- U.S. Grade C or U.S. Standard means lower quality than Grade Ba thrifty buy when optimum appearance and texture are not too important.

Only products that have been officially inspected and packed in plants approved by USDA may be labeled with the U.S. grade designation.

USDA's voluntary grade standards complement mandatory Federal standards designed for consumer protection. For example, the Food and Drug Administration has established minimum standards of quality for several major fruit and vegetable products. So USDA adopts, as the minimum grade level, specifications that are at least as high as FDA's mandatory requirements. This minimum grade is Grade $C$ when the U.S. standards for a product provide three levels of quality and Grade $B$ in those standards where only two levels of quality are provided. Thus USDA provides two or more grade levels for marketing purposes and at the same time recognizes the minimum mandatory standards established by FDA.

USDA has also developed standards for condition of food containers. These standards are used primarily by State and Federal agencies in their food purchase programs. However, large volume food buyers may also request that USDA inspectors use these standards to certify the condition of the containers of the food they are purchasing.

single copies of USDA's grade standards and standards for condition of containers are available free, on request, from the Washington, D.C., office of the inspection service.

\section{Plant Survey}

Before USDA will begin in-plant inspection services, a plant survey is required. USDA also requires a plant survey if a processor wishes to use a U.S. grade designation on the label of products inspected on a lot basis. Only products processed in approved plants may use U.S. grade labeling.

In addition to the initial plant survey, surveys must be repeated at least annually if you wish to continue USDA inspection or official grade labeling.

The plant survey is based on the Food and Drug Administration's good manufacturing practices sanitation guidelines and regulations issued under the Federal Food, Drug, and Cosmetic Act. After passing a plant survey, a processor-and his customers-can be assured that his plant meets rigid sanitary requirements for facilities, equipment, and operating methods.

During a plant survey, USDA inspectors check equipment, facilities, and operating methods to be sure they meet rigid sanitary requirements. 
Pack Certification-Under this program, the inspector is not necessarily present during all operating shifts. He may inspect and certify the entire pack under a cooperative Quality Assurance Program in plants which qualify or he may inspect and certify only designated portions of production.

Lot Inspection-The inspector will check specific lots for quality and condition of the food product and container. The lot can be any size and located in places other than a processing plant.

Unofficial Sample Inspection-Inspection will be made of samples which you select and submit to the nearest USDA inspection office.

In addition, USDA offers volume buyers a service under which USDA representatives will help them write their purchase specifications and will certify the quality and condition of their orders either prior to shipment or when they arrive.

These inspection and grading services play an important role in the orderly marketing of canned, frozen, and dried fruits and vegetables. And the application of the U.S. standards and other specifications by highly trained USDA inspectors assures processors, buyers, and sellers of an impartial, third-party certification of quality.

\section{U.S. Grade Standards- Yardsticks of Quality}

Specialists in USDA have developed U.S. grade standards for some 150 processed fruit and vegetable products.

These U.S. standards are the yardsticks used by USDA's inspectors when you request official inspection based on the U.S. grades. The standards also provide the industry with a common trading language, a guide for in-plant quality control, and a convenient basis for sales.

In addition to certifying the quality, quantity, and condition of fruit and vegetable products, USDA inspectors will also check the condition of the food containers.

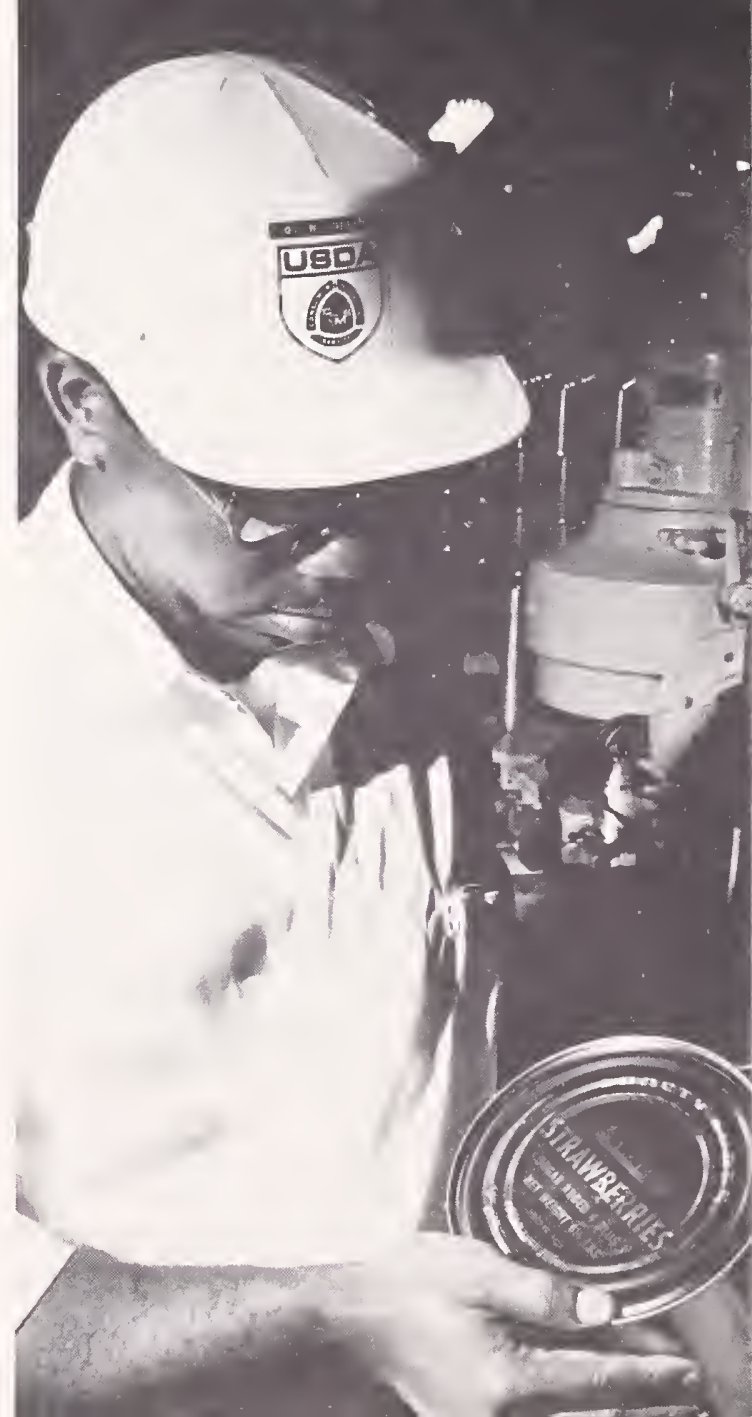




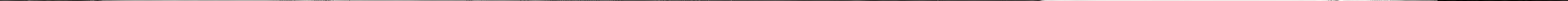


The inspector making the plant survey reports the results of the survey in writing to a designated plant official, and, when the plant meets the required sanitary and other standards, inplant inspection services may begin.

\section{Continuous Inspection}

For continuous inspection, one or more USDA inspectors will be assigned to a processing plant at all times it is operating to make continuous inprocess checks on preparation, processing, and packing operations.

The inspector observes the preparation of raw materials and the plant conditions under which the product is being prepared, processed, and packed. The inspector makes frequent line checks of the quality of the product as it is processed. And he examines samples of the finished product to determine whether they meet U.S. grade standards or other specifications.

The inspector gives the processor daily reports on the grade of the prod- uct being packed as well as plant sanitation conditions. On the basis of these reports, the processor can take immediate action to correct problems before they become serious and impair the quality level of the pack.

After the inspector finishes his examinations and detailed analyses, he issues inspection certificates or other official reports showing the results of the product inspection.

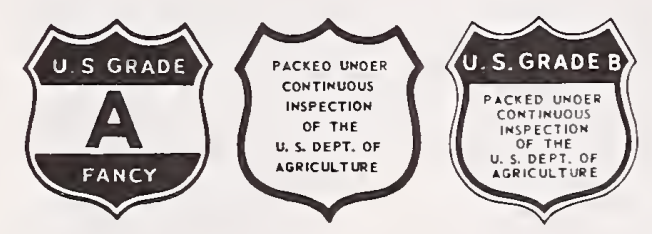

Products packed in any plant operated under the continuous inspection program may be labeled with the official USDA grade marks. The label may carry the familiar shield with the statement "Packed under continuous inspection of the U.S. Department of Agriculture," an otricial grade designa- tion like "U.S. Grade A," or both. The packer may also refer to continuous inspection in his advertising and sales programs.

\section{Pack Certification}

This type of inspection service is similar to continuous inspection except that the inspector need not be present continuously during all operating shifts of the plant. While he is on duty, however, the inspector may perform the same functions as he would under continuous inspection. His responsibilities vary, depending on the needs of the processor. He may certify the entire production through a cooperative quality assurance program.

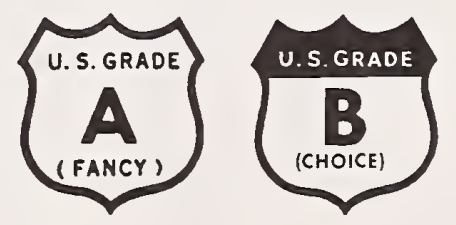


(This program is available to packers who have a quality control program meeting USDA requirements.) Or, if the packer prefers, the inspector may certify only designated production lots.

Processors may use this in-plant inspection service-like continuous inspection-as part of their quality control programs as well as to facilitate sales.

Products inspected under this service can carry the official grade names within the official shield but no reference to continuous inspection may be used.

\section{Lot Inspection}

Anyone with a financial interest can request inspection of specific lots of processed fruits or vegetables. The lots can be of any size and located in proc-

\section{U. S. GRADE A}

\section{U.S. CHOICE}

essing plants, warehouses, or cold storage plants - in producing areas, in transit, or terminal markets.

The inspector will check the condition of the containers, draw a prescribed number of sample containers from the lot, and examine the contents to determine the quality and condition of the product. The results of the inspection are reported to you on an official certificate.

Official grade names, such as U.S. Grade A or U.S. Choice-but not the shield-may be used on products that have been graded and certified on a lot basis if the plant in which the products were processed was approved in a plant survey.

\section{Unofficial \\ Sample Inspection}

Under this program, a processor can select his own samples and submit them to the nearest inspection office for examination.

This type of inspection is most helpful as an aid to a plant's quality control program. However, it is not recommended for negotiating sales because the certificate shows only the grade of the submitted sample-no reference is made to the lot from which the sample was drawn.

No official grade names may be used on products inspected under this program.

\section{Service for \\ Volume Food Buyers}

In addition to providing quality, quantity, and condition certification, USDA will also help volume buyers translate their needs into exact purchase specifications. These specifications can be based on official USDA grade standards as well as a buyer's own specific requirements. Buyers can use these specifications for letting a contract and for calling for bids from suppliers. In the contract with his supplier, a buyer can specify that all purchases must be certified by USDA. 


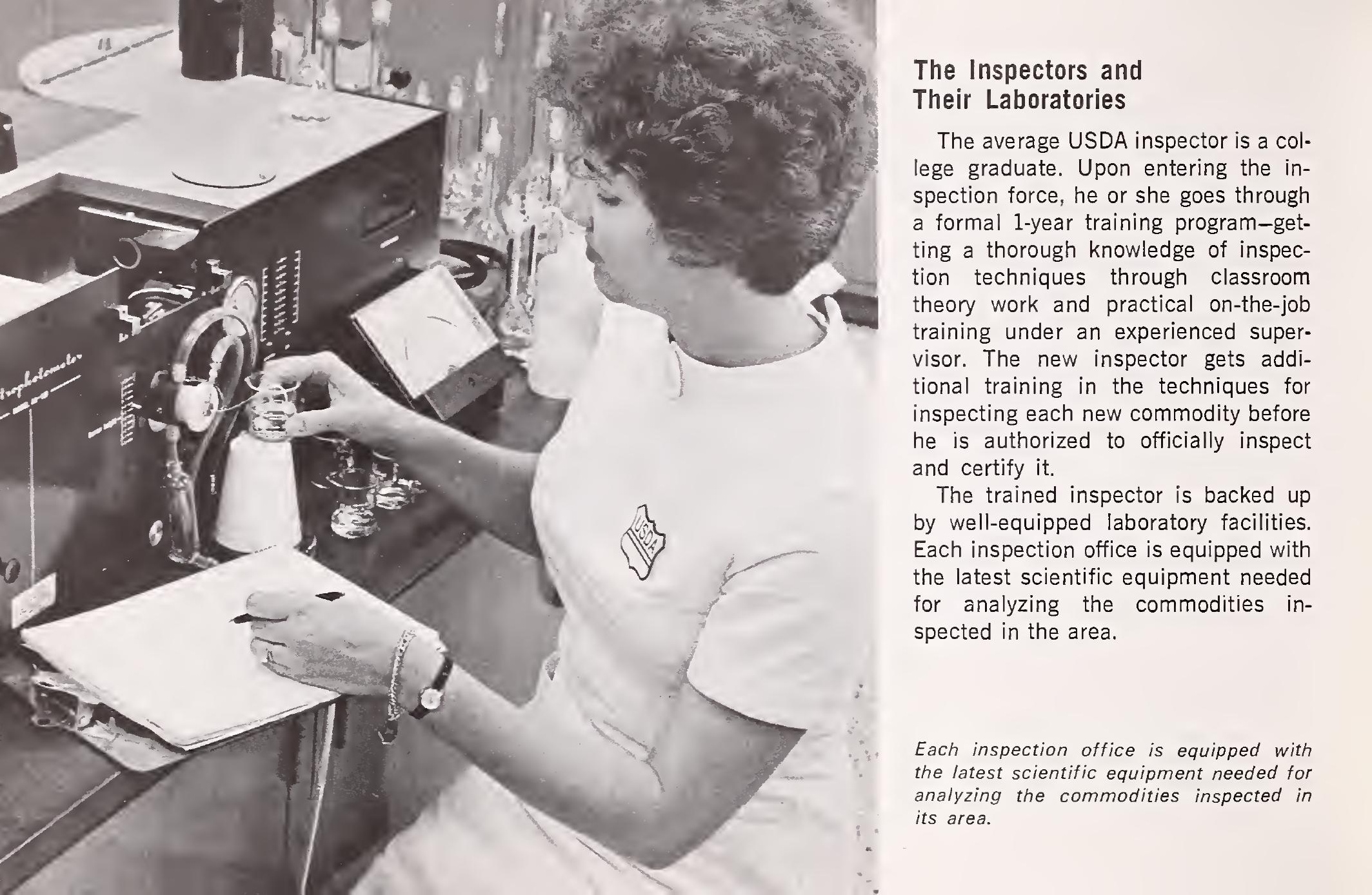




\section{Quality Control Aids}

USDA has developed a number of visual aids, color standards, and guides for uniform interpretation of the various quality factors in the U.S. grade standards. While these were designed primarily for use by the inspection service, many of them are also available to you as an industry member. Processors, particularly, find these visual aids and color guides valuable tools in maintaining quality control during their processing operations.

Among the types of visual aids used by the inspection force are wax models depicting shape, color, types of defects; special plastic and glass color comparators; photographic color slides and prints; and black and white photographs and drawings. USDA has granted licenses to qualified firms to manufacture and sell some of these visual aids. You can get details on available aids and the firms who manufacture them from the inspection office nearest you.

USDA has also developed two standards for statistical procedures. One standard covers inspection by variables (those characteristics that can be measured against a specified requirement). This standard contains certain basic information such as definitions of statistical terms and symbols, the recording of data and the principles of acceptance and rejection. The other standard supplements the first and is of an instructional nature specific for the determination of the amount of fruit or vegetable ingredients filled into a container at the time of processing. Together these standards represent a part of USDA's efforts to use new concepts for product control in its standardization and inspection programs. They are also available for use by processors. You can get details on the standards and find out how they can fit into your quality control program by contacting the Washington, D.C., office of the inspection service.

\section{Relationship with FDA}

USDA's processed fruit and vegetable inspection is a service activity, administered by USDA's Agricultural

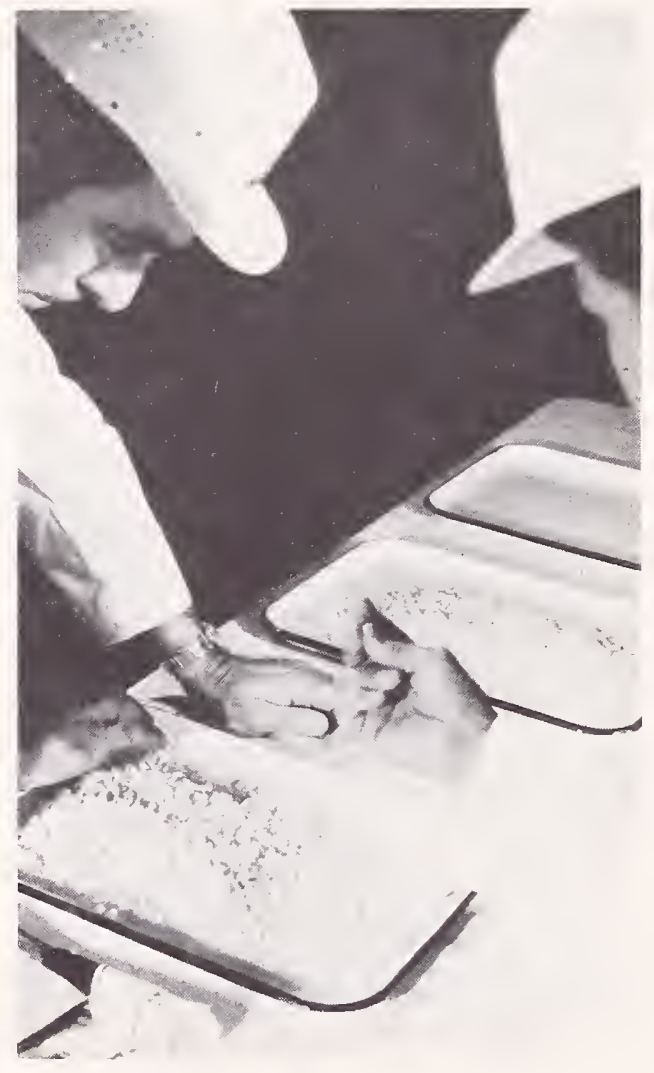

USDA inspectors check quality of samples of frozen corn. 
Marketing Service. Its major purpose is to assist processors in preparing better quality products and to provide official certification concerning the grade or condition of a product which will be useful to all interested parties engaged in the marketing function.

The Food and Drug Administration, on the other hand, is a regulatory agency in the Department of Health, Education, and Welfare. FDA is charged with enforcing the Federal Food, Drug, and Cosmetic Act. USDA-inspected products are, of course, subject to compliance with this Act. Representatives of the two agencies strive for a common understanding and evaluation of conditions generally relating to food plant sanitation and product wholesomeness.

\section{HOW TO OBTAIN OFFICIAL INSPECTION}

For further information regarding inspection services, contact the Officerin-Charge, Processed Products Standardization and Inspection Branch,
Fruit and Vegetable Division, Agricultural Marketing Service, U.S. Department of Agriculture, at the field office nearest you.

\section{ARKANSAS}

P.O. Box 970

Fayetteville, Arkansas 72701

(501) 443-2301, ext. 573

\section{CALIFORNIA}

1130 "O" St., Rm. 3408

Fresno, California 93721

(209) $487-5000$, ext. 210

312 N. Spring St., Rm. 1535

Los Angeles, California 90012

(213) $688-3173$

390 Main St., Rm. 7093

San Francisco, California 94105

(415) $556-4802$

1438 S. First St.

San Jose, California 95110

(408) $275-7468$

5635 Stratford Circle, Suite 11

Stockton, California 95207

(209) 946-6281
COLORADO

353 U.S. Custom House

Denver, Colorado 80202

(303) $837-3160$

\section{FLORIDA}

P.O. Box 860

Winter Haven, Florida 33880

(813) $294-7416$

\section{GEORGIA}

1555 St. Joseph Ave.

East Point, Georgia 30344

(404) 526-7495

HAWAII

P.O. Box 5425

Honolulu, Hawaii 96814

(808) 941-3071

\section{ILLINOIS}

U.S. Custom House, Rm. 1014

610 S. Canal St.

Chicago, Illinois 60607

(312) 353-6217

\section{LOUISIANA}

Box 159

Hammond, Louisiana 70401

(504) 345-6060 
MAINE

26 Forest Ave.

Portland, Maine 04101

(207) 775-3131, ext. 243

\section{MARYLAND}

534 Appraisers Stores Bldg. Baltimore, Maryland 21202

(301) 962-2474

102 Maryland Ave.

Easton, Maryland 21601

(301) 822-3383

\section{MICHIGAN}

Rm. 2-1-58, Federal Center

74 N. Washington Ave.

Battle Creek, Michigan 49017

(616) 962-6511, ext. 6349

\section{NEW YORK}

201 Varick St., Rm. 1011

New York, New York 10014

(212) $620-5716$

900 Jefferson Rd.

Rochester, New York 14623

(716) 244-2266
$\mathrm{OHIO}$

P.O. Box 512

Van Wert, Ohio 45891

(419) 238-4105

\section{OREGON}

P.O. Box 5345

Salem, Oregon 97304

(503) 585-1793, ext. 248

\section{PENNSYLVANIA}

601 U.S. Custom House

Second \& Chestnut Sts.

Philadelphia, Pennsylvania 19106

(215) $597-4520$

PUERTO RICO

P.O. Box 10163

Santurce, Puerto Rico 00908

(809) 783-4116

\section{TEXAS}

P.O. Box 1123

Weslaco, Texas 78596

(512) $968-2772$

UTAH

B-45, State Capitol BIdg.

Salt Lake City, Utah 84114

(801) 328-5421
VIRGINIA

No. 1 N. Fourteenth St., Rm. 332

Richmond, Virginia 23219

(804) $770-2422$

WASHINGTON

1917 First Ave., Rm. 207

Seattle, Washington 98101

(206) $442-7525$

212 Liberty Bldg.

Yakima, Washington 98901

(509) 248-4810, ext. 331

WISCONSIN

P.O. Box 96

Ripon, Wisconsin 54971

(414) $748-2287$

Single copies of U.S. grade standards for processed fruit and vegetable products and standards for condition of containers are available from:

Processed Products Standardization and Inspection Branch

Fruit and Vegetable Division Agricultural Marketing Service U.S. Department of Agriculture Washington, D.C. 20250 (202) 447-4693 
All AMS services are available without regard to race, color, creed, sex, or national origin. If you know of any violations of this principle, send details to the Secretary of Agriculture, Washington, D.C. 20250.
For sale by the Superintendent of Documents, U.S. Government Printing Office, Washington, D.C. 20402 . Price 30 cents. Stock Number 0100-03380

This publication supersedes PA-803, "Processed Fruit and Vegetable Inspection at Your Service," issued April 1967.

January 1975 